\title{
The interference of Moringa oleifera leaf extracts to modulate quorum sensing-facilitated virulence factors
}

\author{
SUHARTONO SUHARTONO ${ }^{\natural}$, YULIA SARI ISMAIL, SYARIFAH RAISHA MUHAYYA \\ Department of Biology, Faculty of Mathematics and Natural Sciences, Universitas Syiah Kuala. Jl. Tgk Syech Abdurrauf No.3, Banda Aceh 23111, \\ Aceh, Indonesia. Tel./fax.: +62-651-7410248, `email: suhartono@unsyiah.ac.id
}

Manuscript received: 5 September 2019. Revision accepted: 20 September 2019.

\begin{abstract}
Suhartono S, Ismail YS, Muhayya SR. 2019. The interference of Moringa oleifera leaf extracts to modulate quorum sensingfacilitated virulence factors. Biodiversitas 20: 3000-3004. The infections attenuated by the presence of virulence factors might be facilitated by quorum sensing (QS) mechanism. The continuous treatments of bacterial infections with current drugs, however, has developed such pathogenic bacteria more antibiotic-resistant, encouraging to searching for better alternative treatment, such as the use of plant-derived bioactive constituents, including kelor (Moringa oleifera L.). In the present research, kelor (M. oleifera) ethanolic leaf extract was evaluated for their potency as an antibacterial agent to inhibit bacterial virulence factors mediated by quorum sensing mechanism against Chromobacterium violaceum and Pseudomonas aeruginosa PAO1. A phytochemical examination of $M$. oleifera leaf-ethanolic extracts has been conducted resulting positive detection of alkaloids, steroids, terpenoids, flavonoids, and phenolics or tannins. The extracts had MIC and MBC values of $10 \mathrm{mg} / \mathrm{mL}$ and $20 \mathrm{mg} / \mathrm{mL}$, respectively, for both tested bacteria. The ethanolic extracts of $M$. oleifera leaves also showed potent inhibition of quorum sensing by significantly reducing violacein and pyocyanin production as well as interference of swarming motility and biofilm formation.
\end{abstract}

Keywords: Moringa oleifera, quorum sensing, virulence factors

\section{INTRODUCTION}

Bacterial infections are still a major concern generating significant implications in various circumstances. The infections are attenuated by the presence of virulence factors facilitated by quorum sensing (QS) mechanism leading to the increasing pathogenicity and persistence of the infection. The QS mechanism allows the bacteria to have a cell to cell signaling and communication to express particular genes, i.e. virulence factors, after reaching a specific threshold of population density (Kalia 2013). The bacterial cells release and detect small molecules known as autoinducers (AIs) that modulate the behavior expression of virulence factors including biofilm formation, swarming motility, and bioluminescence (Ćirić et al. 2018). Biofilmformation, for instance, has been associated with the occurrence of antibiotic-resistant pathogenic bacteria leading to the skyrocketing annually burden of healthcare to be $\$ 94$ billion with more than a half of million death (Wolcott et al. 2010).

The continuous treatment of bacterial infections with current drugs, however, has developed such pathogenic bacteria, in sessile form or in a biofilm structure, to be more antibiotic-resistant (Llor and Bjerrum 2014). This encourages to searching for better alternatives for treatment, such as the use of natural molecules or plantderived products. These phytochemicals, including kelor (Moringa oleifera L.) leaves, have been studied for their potency to inhibit microbial infections (Abdulkadir et al. 2018) and draw more attention as a modulatory agent in interference of QS signaling (Koh et al. 2013; Noumi et al. 2017). M. oleifera is a herb originally from Sub Himalayan mountains of Northern India and is widely spread in the lowlands and highlands of tropical and subtropical countries (Saini et al. 2016). M. oleifera leaves are ovalshaped with small sizes arranged compound in a single stalk with flowers which are yellowish-white with the green hood and bloomed all year long (Alegbeleye 2017). Moreover, M. oleifera recognized as the miracle plant is globally used for various purposes including food ingredients, medicines, water purification, animal fodder, fertilizer, and biofuel (Daba 2016). In Indonesia, M. oleifera leaves have been ethnobotanically consumed as vegetables with distinctive flavors and applied as traditional medicines to treat high blood pressure (Bahriyah et al. 2015). In Aceh, M. oleifera is traditionally used as a fever remedy in addition to as foods and medicines in Pulo Breueh tribe (Wardiah et al. 2015). In addition, the later study revealed that $M$. oleifera leaves are known to have phytoactive compounds showing their potentials to be antimicrobial agents (Shahriar et al. 2012). It is speculated that biological function of plant-derived compounds are considered as safe and not trigger any toxicity effects on human cells (Koh et al. 2013).

The objectives of the research were to analyze the phytochemical compounds of $M$. oleifera leaf extracts (MLE) and to evaluate their potency to inhibit bacterial virulence factors mediated by quorum sensing mechanisms, such as biofilm formation. 


\section{MATERIALS AND METHODS}

\section{Plant material and extraction}

A total of five kilograms of kelor (Moringa oleifera $\mathrm{L}$.) leaves were collected from Aceh Besar, Indonesia and then were cleaned and washed. The leaves were then air-dried for four weeks followed by grinding and sieving into powder. The simplicial powder was then extracted using maceration method in 1: 10 ratio. A total of $600 \mathrm{~g}$ of simplicial was mixed and homogenized in a flask containing six litters of ethanol; sealed and incubated for five days. The mixture was then filtered to yield macerates and lees. The resulting macerates were stored in a place protected from light; while the lees were undergone the same maceration process for another five days using $1.5 \mathrm{~L}$ ethanol. All the obtained macerates were concentrated using a rotary evaporator at temperatures below $50^{\circ} \mathrm{C}$ to obtain a $100 \%$ concentrate.

\section{Phytochemical screening}

Phytochemical screening assay of ethanolic extract of $M$. oleifera leaves was intended to examine various phytochemical contents found in them. The extract samples were qualitatively analyzed, including the presence of alkaloid, flavonoid, terpenoid, as well as tannin compounds.

\section{Bacterial strains and culture condition}

Pseudomonas aeruginosa PAO1 and Chromobacterium violaceum were used in this study to determine the effect of ethanolic extracts of $M$. oleifera leaves. All bacterial strains were cultivated and maintained in Luria Bertani (LB) (Difco, USA), Mueller Hinton Broth (Difco, USA), Mueller Hinton Agar (Difco, USA), and Tryptic Soy Agar (Oxoid, UK) and incubated at $30^{\circ} \mathrm{C}(C$. violaceum) and 37 ${ }^{\circ} \mathrm{C}(P$. aeruginosa $)$.

\section{Antibacterial activity}

Antibacterial activity of $M$. oleifera leaf extract was conducted using a previously described method (Hossain et al. 2015). The extracts were determined for their minimum inhibitory concentration (MIC) and minimum bactericidal concentrations (MBC). Briefly, various concentrations $(0.31,0.63,1.25,2.50,5.00,10.00$, and $20,00 \mathrm{mg} / \mathrm{mL})$ of $M$. oleifera leaf extracts as well as tetracycline (a concentration range of $0.50-256.00 \mathrm{mg} / \mathrm{mL}$ ) as positive control were inoculated into separate walls of 96-well microplates before adding the target bacteria inoculum with densities of $5 \times 10^{5} \mathrm{CFU} / \mathrm{mL}$ and incubated for $24 \mathrm{~h}$. The MIC was determined by the lowest concentration of the extract inhibiting the increment bacterial number compared to the initial number of bacteria. The $\mathrm{MBC}$ was determined by inoculating $20 \mu \mathrm{L}$ of the $\leq$ MIC wells onto MHA plates and incubated for $24 \mathrm{~h}$ at room temperature. MBCs were considered as the lowest concentrations that inhibit the bacterial target growth completely.

\section{Quorum sensing inhibition}

Quorum sensing inhibition was conducted through violacein quantification, pyocyanin inhibition, swarming motility inhibition, and biofilm viability assay.
Violacein quantification was performed following a previously described method (Hossain et al. 2015). A concentration range ( $1 / 2 \times \mathrm{MIC}, 1 \times \mathrm{MIC}$, and $2 \times \mathrm{MIC})$ of M. oleifera extract as well as $10 \mu \mathrm{g} / \mathrm{mL}$ of $3 \% \mathrm{H}_{2} \mathrm{O}_{2}$ as a positive control was transferred into flasks containing $\mathrm{LB}$ broth before they were inoculated with $5 \times 10^{5} \mathrm{CFU} / \mathrm{mL}$ of C. violaceum culture. The flasks were then incubated at 30 ${ }^{\circ} \mathrm{C}$ with $150 \mathrm{rpm}$ in a shaking incubator for $24 \mathrm{~h}$ before the violacein was extracted and quantified using the previous method (Choo et al. 2006).

Pyocyanin inhibition was determined by overnight culturing of $P$. aeruginosa in $5 \mathrm{~mL}$ of $\mathrm{LB}$ broth supplemented with various concentration range (1/2x MIC, $1 \times$ MIC, and $2 \times$ MIC) of M. oleifera leaf extracts. The culture was then centrifuged at $10.000 \mathrm{x}$ g for $10 \mathrm{~min}$ and the supernatant was collected before mixing with $3 \mathrm{~mL}$ of chloroform. The aqueous part was removed and mixed with $0.2 \mathrm{M} \mathrm{HCl}$ before the mixture was homogenized and centrifuged. The formed pink layer was collected and measured for its optical density at $520 \mathrm{~nm}$.

Inhibition of swarming motility was conducted by inoculating $P$. aeruginosa onto the center of LB agar plates containing $0.50 \%$ agar and $0.50 \%$ glucose supplemented with various concentration range (1/2x MIC, 1 x MIC, and $2 \times$ MIC) of $M$. oleifera leaf extracts. The plates were then incubated for $48 \mathrm{~h}$ at $37^{\circ} \mathrm{C}$ and the swarm zone was calculated.

The biofilm viability was assayed after overnight culturing $P$. aeruginosa in a 96-well microplate containing $10 \mu \mathrm{L} \mathrm{LB}$ broth and $0.5 \%$ glucose. After incubation, the plates were rinsed with $1 \times$ PBS (phosphate buffer saline) solution and transferred into new plates containing various concentration range (1/2x MIC, $1 \times$ MIC, and $2 \times$ MIC) of M. oleifera leaf extracts in LB broth. After incubation ( $24 \mathrm{~h}$ at $37{ }^{\circ} \mathrm{C}$ ), the microplate was washed three times with sterile phosphate buffer saline (PBS). A $200 \mu \mathrm{L}$ of $95 \%$ ethanol was gently poured in the microplate and left for 15 minutes before draining and drying. The staining process was conducted using $125 \mu \mathrm{L}$ of $0.1 \%$ crystal violet for 10 15 minutes, rinsed off using sterile distilled water and dried for several hours. The dried microplate was then filled with $125 \mu \mathrm{L}$ of $30 \%$ glacial acetic acid and incubated for 15 minutes. A total $125 \mu \mathrm{L}$ of the $30 \%$ glacial acetic acid was added and the optical density (OD), which described the quantity of biofilm formation, was measured at a wavelength of $570 \mathrm{~nm}$ using a microtiter plate reader (BioRad, CA, USA).

\section{Statistical analysis}

Data were presented as mean \pm standard deviation of two replicate assay. An analysis of variance (ANOVA) was conducted for the determination of statistical significance using XLSTAT2016 (Addinsoft, New York). P-values of less than 0.05 were considered to be statistically significant and different letter depicted the statistical significance. 


\section{RESULTS AND DISCUSSION}

\section{Extraction of Moringa oleifera leaves}

The total extract and the total extraction yield obtained from a $900 \mathrm{~g}$ of simplicial of $M$. oleifera leaves by $96 \%$ ethanol were $210.5 \mathrm{~g}$ and $23.38 \%$, respectively. The phytochemical screening of ethanolic extract of $M$. oleifera leaves was carried out qualitatively. The extracts revealed the presence of flavonoids, phenols (tannins), terpenoids, steroids, and alkaloids; whereas saponins were absent (Table 1).

\section{Bacterial inhibition}

The MIC and MBC of ethanolic extracts of $M$. oleifera leaves against $C$. violaceum and $P$. aeruginosa are shown in Table 2. The MIC of ethanolic extracts of $M$. oleifera leaves was $10.00 \mathrm{mg} / \mathrm{mL}$ against both $C$. violaceum and $P$. aeruginosa. The MBCs of the extracts against both the tested bacteria were twice their MICs $(20 \mathrm{mg} / \mathrm{mL})$.

\section{Quorum sensing inhibition}

Quorum sensing inhibition consisted of violacein quantification, pyocyanin inhibition, swarming motility inhibition, and biofilm viability assay. The percent violacein inhibitions were $29.91 \%, 41.88 \%$, and $73.03 \%$ in $1 / 2 \times \mathrm{MIC}, 1 \times \mathrm{MIC}$, and $2 \times \mathrm{MIC}$ of $M$. oleifera extracttreated cultures, respectively, compared to the negative control without addition of the extract. The positive control, $\mathrm{H}_{2} \mathrm{O}_{2} 3 \%$-treated culture inhibited $99.87 \%$ of violacein pigment. There was a significant effect on the addition of the ethanolic $M$. oleifera leaf extracts towards the violacein production of $C$. violaceum (Figure 1).

Pyocyanin production inhibition against $P$. aeruginosa supplemented with various concentration range $(1 / 2 \mathrm{x}$ MIC, $1 \mathrm{x}$ MIC, and $2 \times \mathrm{MIC}$ ) of $M$. oleifera leaf extracts is shown in Figure 3. The corresponding percent pyocyanin inhibitions were $27.94 \%, 83.72 \%, 94.59 \%$ in $1 / 2 \times$ MIC, 1 $\mathrm{x}$ MIC, and 2 x MIC of $M$. oleifera extract-treated cultures, whereas $\mathrm{H}_{2} \mathrm{O}_{2} 3 \%$ inhibited $90.85 \%$ of violacein pigment. There was a significant effect on the addition of the ethanolic $M$. oleifera leaf extracts towards the pyocyanin production of $P$. aeruginosa (Figure 2).

The swarming motility for $P$. aeruginosa treated with ethanolic extract of $M$. oleifera leaves is presented in Figure 3. The inhibition of swarming motility was $18 \mathrm{~mm}$, $10 \mathrm{~mm}$, and $15 \mathrm{~mm}$ in $1 / 2 \times \mathrm{MIC}, 1 \mathrm{x} \mathrm{MIC}$, and $2 \times \mathrm{MIC}$ of $M$. oleifera extract-treated isolate, respectively, compared negative control which had $24.5 \mathrm{~mm}$.

The result for biofilm availability assay is shown in Figure 4. There was a significant effect on the addition of the ethanolic $M$. oleifera leaf extracts towards the biofilm activity of $P$. aeruginosa. The $M$. oleifera extract-treated cultures with $1 / 2 \times$ MIC, $1 \times$ MIC, and $2 \times$ MIC had respective percent biofilm inhibitions of $16.89 \%, 12.40 \%$, $51.10 \%$, compared to the negative control without addition of the extract. The positive control of $\mathrm{H}_{2} \mathrm{O}_{2} 3 \%$-treated culture inhibited $90.85 \%$ of biofilm formation.
Table 1. The phytochemical analysis of ethanolic extracts of $M$. oleifera leaves

\begin{tabular}{ll}
\hline Phytochemical assays & Results \\
\hline & \\
Alkaloids & Positive \\
Steroids & Positive \\
Terpenoids & Positive \\
Saponins & Negative \\
Flavonoid & Positive \\
Phenolics/Tannins & Positive
\end{tabular}

Table 2. Minimum inhibitory concentration (MIC) and minimum bactericidal concentration (MBC) of ethanolic extracts of $M$. oleifera leaves against $C$. violaceum and $P$. aeruginosa (PAO1)

\begin{tabular}{lcc}
\hline Bacterial targets & $\begin{array}{c}\text { MIC } \\
(\mathbf{m g} / \mathbf{m L})\end{array}$ & $\begin{array}{c}\text { MBC } \\
(\mathbf{m g} / \mathbf{m L})\end{array}$ \\
\hline Chromobacterium violaceum & 10 & 20 \\
Pseudomonas aeruginosa PAO1 & 10 & 20 \\
\hline
\end{tabular}

\section{Discussion}

Searching for natural-based product to overcome bacterial pathogens is growing due to the increasing rate of the pathogens in terms of their resistance and virulence. Plant-derived bioactive compounds become potential option since the plants are rich in phytochemicals possessing antimicrobial activities. Additionally, plantderived constituents are also superior to others since they are produced by the plants that lack immune systems and may have evolved to secrete anti-QS or quorum quenching compounds used to overcome QS pathogens (Koh et al. 2013). One of the plants possessing bioactive compounds is M. oleifera. Almost all parts of M. oleifera have been widely known for its nutritional and functional features as a food source as well as medicine (Saini et al. 2016; Abdulkadir et al. 2018). The mechanism of how the plant reduced the bacterial infections also gains more attention, particularly those who are mediated by quorum sensing mechanism such as biofilm formation. In the present study, M. oleifera leaf extracts were evaluated for their potency to inhibit bacterial quorum sensing-based virulence factors.

The ethanolic extracts of $M$. oleifera leaves revealed the presence of flavonoids, phenols (tannins), terpenoids, steroids, and alkaloids; whereas saponins were absent (Table 1). This finding is in accordance with another study (Ikalinus et al. 2015) suggesting phytochemical screening of $M$. oleifera leaves showed positive results for all the mentioned compounds, except for saponins. Some of the phytochemicals, such as flavonoids, harbor significant disruption properties for biofilm formation (Raorane et al. 2019). 


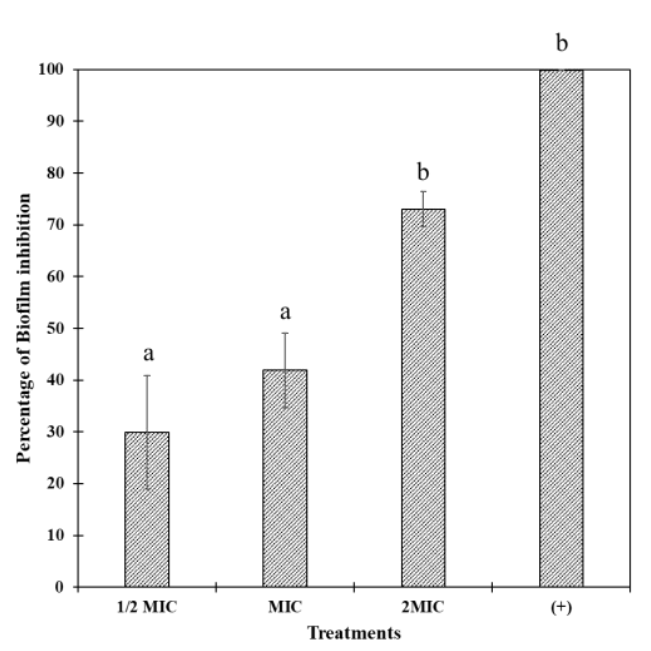

Figure 1. The percent violacein inhibitions of $C$. violaceum treated with ethanolic extracts of $M$. oleifera leaves with the concentration of $1 / 2$ MIC $(5 \mathrm{mg} / \mathrm{mL}), 1 \times$ MIC $(10 \mathrm{mg} / \mathrm{mL})$, and 2 $x$ MIC $(20 \mathrm{mg} / \mathrm{mL})$. (+): positive control of the addition of $\mathrm{H}_{2} \mathrm{O}_{2}$ $3 \%$. The treatments followed by the same letters above each column are not significantly different $(\mathrm{P} \leq 0.05)$

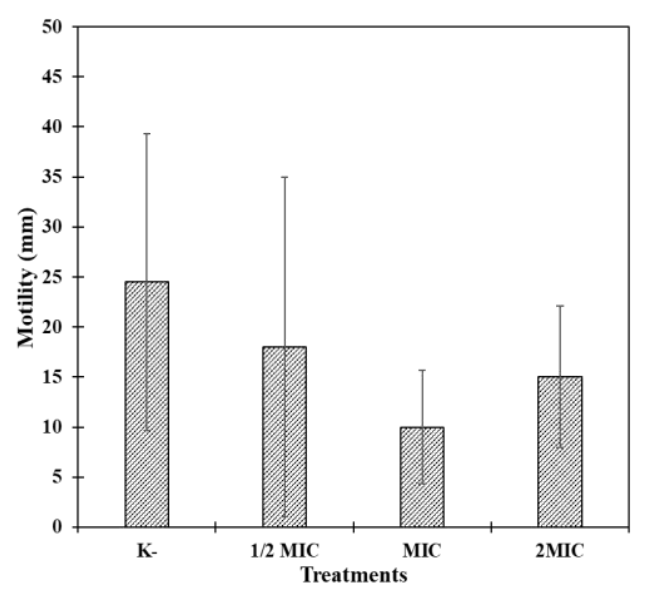

Figure 3. The inhibition of swarming motility of $P$. aeruginosa PAO1 treated with ethanolic extracts of $M$. oleifera leaves with the concentration of $1 / 2$ MIC $(5 \mathrm{mg} / \mathrm{mL}), 1 \times$ MIC $(10 \mathrm{mg} / \mathrm{mL})$, and $2 \times$ MIC $(20 \mathrm{mg} / \mathrm{mL})$. (K-): negative control M. oleifera extract-free $P$. aeruginosa.

In the present study, the MLE showed Gram-negative bacterial inhibition at the lowest concentration of 10 $\mathrm{mg} / \mathrm{mL}$ (Table 2). This result was aligned with the previous study (Hossain et al. 2017) highlighting the same MIC value for their $N$. tetragona extracts against $P$. aeruginosa which had slightly higher concentration than the recommended maximum efficiency concentration of 8.0 $\mathrm{mg} / \mathrm{mL}$ (Ncube et al. 2012). This might indicate the potency of MLEs application as a modulating agent for quorum sensing-based virulence factor.

For the quantitative study of the pigment production of violacein, the present study exhibited significant inhibitions

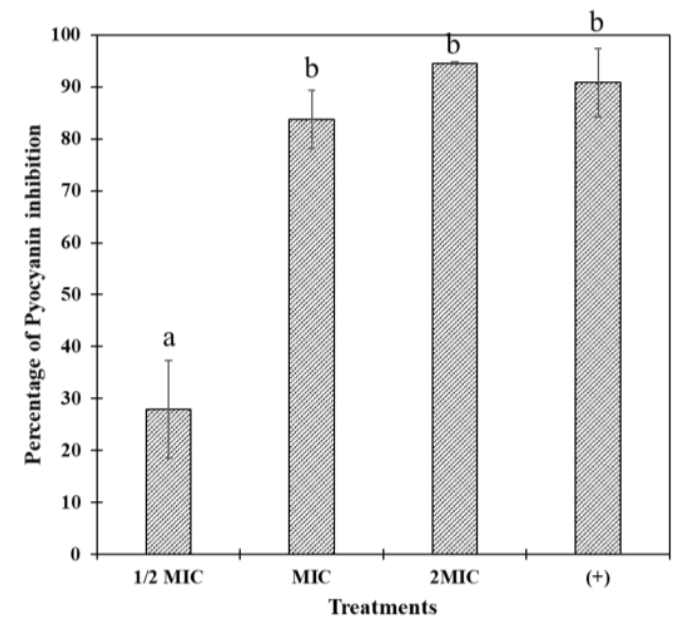

Figure 2. The percent pyocyanin inhibitions of $P$. aeruginosa PAO1 treated with ethanolic extracts of $M$. oleifera leaves with the concentration of $1 / 2$ MIC $(5 \mathrm{mg} / \mathrm{mL}), 1 \times$ MIC $(10 \mathrm{mg} / \mathrm{mL})$, and $2 \times$ MIC $(20 \mathrm{mg} / \mathrm{mL})$. (+): positive control of the addition of $\mathrm{H}_{2} \mathrm{O}_{2} 3 \%$. The treatments followed by the same letters above each column are not significantly different $(P \leq 0.05)$

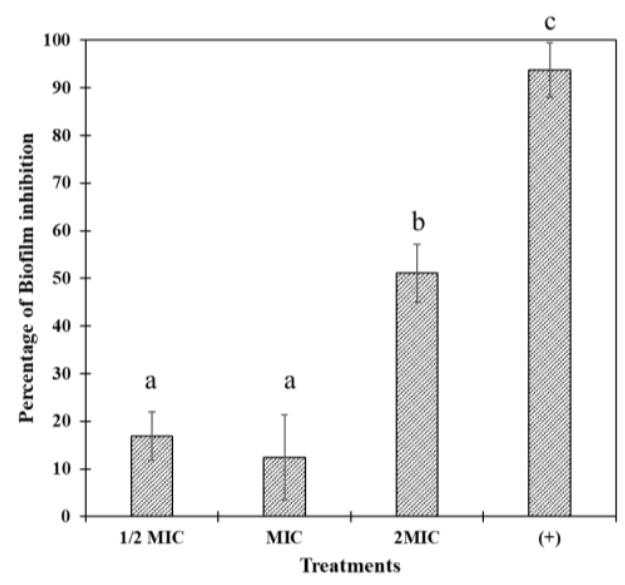

Figure 4. The percentage of biofilm inhibitions of $P$. aeruginosa PAO1 treated with ethanolic extracts of $M$. oleifera leaves with the concentration of $1 / 2$ MIC $(5 \mathrm{mg} / \mathrm{mL}), 1 \times$ MIC $(10 \mathrm{mg} / \mathrm{mL})$, and $2 \times$ MIC $(20 \mathrm{mg} / \mathrm{mL})$. (+): positive control of the addition of $\mathrm{H}_{2} \mathrm{O}_{2} 3 \%$. The treatments followed by the same letters above each column are not significantly different $(P \leq 0.05)$

of $C$. violaceum demonstrating the concentration-dependent MLEs. This result was in line with the previous investigation (Hossain et al. 2017) which reported a similar trend for the crude extract of water lily against $C$. violaceum. This justifies the potentials of MLEs as quorum sensing inhibitors as $C$. violaceum widely used in the quorum-sensing inhibitor assay. Violacein production is QS-regulated by an operon system consisting of set of genes, namely $i o D, v i o C$, vioB and $v i o A$ genes (August et al. 2000) so it is assumed that the extract might affect the regulation of the operon. 
The ability of MLEs to inhibit pyocyanin production and swarming activity was also determined in the current study. Pyocyanin is a blue toxin essential for penetration and it destroys other cells during the $P$. aeruginosa infections, whereas swarming is an orchestrated migration across the surface of solid or semi-solid media facilitated by quorum sensing mechanism. In the present study, the MLEs exhibited a significant dose-dependent inhibition on pyocyanin production (Figure 3) which signifies the fact that MLEs might contain rhl system inhibitory properties that disrupt the expression of virulence factors including pyocyanin. In $P$. aeruginosa, virulence factors are synthesized by regulating $r h l$ system comprising of transcriptional activator and autoinducers directing the expression of rhamnolipids and production of secondary metabolites including pyocyanin (De Kievit and Iglewski 2000). Rhamnolipids are one of the decreasing-surface tension chemicals allowing $P$. aeruginosa to have swarming activity in addition to the bacterial physical structures, such as pili and fimbriae (Tremblay and Déziel 2008). A slight difference from pyocyanin production, there is no significant concentration-dependence on the swarming activity in this study (Figure 4). However, the increasing MLEs tended to reduce the migration of $P$. aeruginosa highlighting there might be an interference of the extracts in the flagella-facilitated motility of the bacteria leading to the decreased swarming activity.

Another biological process facilitated by QS mechanisms is in biofilm formation. In the current research, there was a significantly reduced biofilm formation in a concentration-dependent fashion (Figure 4). The extract might play role in the disruption of bacterial attachment on the surface as this step is critical for bacteria to initiate a biofilm formation. Moreover, some of the phytochemicals, such as flavonoids, contained in the $M$. oleifera extract have been declared to possess anti-biofilm activities toward Staphylococcus aureus due to its ability to inhibit intercellular adhesion genes icaA and icaD (Lee et al. 2013), a significant disruption factor for biofilm formation.

In conclusion, the activity of MLEs on the interruption of bacterial growth as well as QS-facilitated virulence factors including the production of violacein and pyocyanin, swarming motility, and biofilm formation are indicative for providing insights of the potency of $M$. oleifera leaves as a modulating agent for attenuating the expression of the factors leading to decreased infections. Future co-application of this extract along with their existing conventional antimicrobials is promising as the extracts target specific QS-facilitated virulence factors. Further investigation is necessary to elucidate the molecular mechanism of QS interruption of the extract.

\section{ACKNOWLEDGEMENTS}

This study was supported by the Institute of Research and Community Services (LPPM), Universitas Syiah Kuala under the H-indexed Research Grant [No. 523/UN11/ SPK/PNBP/2019].

\section{REFERENCES}

Abdulkadir AR, Hasan MM, Jahan MS. 2018. Antimalarial, antioxidant, antimicrobial properties of Moringa oleifera Lam: a review. Aust J Crop Sci 12: 905-908.

Alegbeleye OO. 2017. How Functional is Moringa oleifera? A review of it's nutritive, medicinal and socioeconomic potential. Food Nutr Bull 20: $1-22$.

August PR, Grossman TH, Minor C, Draper MP, MacNeil IA, Pemberton JM, Call M, Holt D, Osburne MS. 2000. Sequence analyses and functional characterization of the violacein biosynthetic pathway from Chromobacterium violaceum. J Mol Microbiol Biotechnol 2: $513-$ 519.

Bahriyah I, Hayati A, Zayadi H. 2015. Ethnobotanical studies of Kelor (Moringa oleifera) in the village of Somber, sub-district of Tambelangan District of Sampang Madura. Biosci Trop 1: 23382805. [Indonesian]

Choo JH, Rukayadi Y, Hwang JK. 2006. Inhibition of bacterial quorum sensing by vanilla extract. Lett Appl Microbiol 42: 637-641.

Ćirić AD, Petrović JD, Glamočlija JM, Smiljković MS, Nikolić MM, Stojković DS, Soković MD. 2018. Natural products as biofilm formation antagonists and regulators of quorum sensing functions: A comprehensive review update and future trends. S Afr J Bot 120: 6580 .

Daba M. 2016. Miracle tree: a review on multi-purposes of Moringa oleifera and its implication for climate change mitigation. J Earth Sci Clim Change 7: 1-5.

De Kievit TR, Iglewski BH. 2000. Bacterial quorum sensing in pathogenic relationships. Infect Immun 68: 4839-4849.

Hossain MA, Lee SJ, Park JY, Reza MA, Kim TH, Lee KJ, Suh JW, Park SC. 2015. Modulation of quorum sensing-controlled virulence factors by Nymphaea tetragona (water lily) extract. J Ethnopharmacol 174: 482-491.

Ikalinus R, Widyastuti SK, Setiasih NLE. 2015. Identification of chemical compounds ethanol extract leaf moringa (Moringa oleifera 1) in Bali. Indon Med Vet 4: 71-79. [Indonesian]

Kalia VC. 2013. Quorum sensing inhibitors: an overview. Biotechnol Adv 31: 224-245.

Koh CL, Sam CK, Yin WF, Tan YL, Krishnan T, Chong MY, Chan KG. 2013. Plant-derived natural products as sources of anti-quorum sensing compounds. Sensors 13: 6217-6228.

Lee JH, Park JH, Cho HS, Joo SW, Cho MH, Lee J. 2013. Anti-biofilm activities of quercetin and tannic acid against Staphylococcus aureus. Biofouling 29: 491-499.

Llor C, Bjerrum L. 2014. Antimicrobial resistance: risk associated with antibiotic overuse and initiatives to reduce the problem. Ther Adv Drug Saf 5: 229-241.

Ncube B, Finnie JF, Van Staden J. 2012. In vitro antimicrobial synergism within plant extract combinations from three South African medicinal bulbs. J Ethnopharmacol 139: 81-89.

Noumi E, Snoussi M, Merghni A, NazzaroF, Quindós G, Akdamar G, Mastouri M, Al-Sieni A, Ceylan O. 2017. Phytochemical composition, anti-biofilm and anti-quorum sensing potential of fruit, stem and leaves of Salvadora persica L. methanolic extracts. Microb Pathog 109: 169-176.

Raorane CJ, Lee JH, Kim YG, Rajasekharan SK, García-Contreras R, Lee J. 2019. Antibiofilm and antivirulence efficacies of flavonoids and curcumin against Acinetobacter baumannii. Front Microbiol 10: 990.

Saini RK, Sivanesan I, Keum YS. 2016. Phytochemicals of Moringa oleifera: a review of their nutritional, therapeutic and industrial significance. 3 Biotech 6: 1-14.

Shahriar M, Hossain I, Mahar AN, Akhter S, Haque A, Bhuiyan M. 2012. Preliminary phytochemical screening, in-vitro antioxidant and cytotoxic activity of five different extracts of Moringa oleifera Leaf. J Appl Pharm Sci 2: 65-68.

Tremblay J, Déziel E. 2008. Improving the reproducibility of Pseudomonas aeruginosa swarming motility assays. J Basic Microbiol 48: 509-515.

Wardiah, Hasanuddin, Mutmainnah. 2015. Medical ethnobotany of villagers of South Pulo Breuh subdistricts of Pulo Aceh, district of Aceh Besar. J EduBio Tropi 3: 1-50. [Indonesian]

Wolcott RD, Rhoads DD, Bennett ME, Wolcott BM, Gogokhia L, Costerton JW, Dowd SE. 2010. Chronic wounds and the medical biofilm paradigm. J Wound Care 19: 45-53. 